\title{
Desempenho escolar: análise comparativa em função do sexo e percepção dos estudantes
}

Andréia Ostil

Selma de Cássia Martinelli"

\section{Resumo}

0 presente artigo investigou o desempenho escolar em função do sexo e a percepção de alunos em relação às expectativas de seu professor. Participaram da pesquisa 120 alunos do $5^{\circ}$ ano do ensino fundamental de escolas públicas municipais da região metropolitana de Campinas, dos quais 60 alunos têm desempenho escolar satisfatório e 60 têm desempenho insatisfatório. Foi utilizada uma escala de percepção de alunos acerca das expectativas dos professores; já para medir o desempenho escolar foi considerado o conceito atribuído pelo professor ao aluno. Os resultados revelaram diferenças significativas entre meninos e meninas do grupo de alunos com desempenho insatisfatório, pois a maioria $(83,3 \%)$ era do sexo masculino. Por outro lado, não se verificaram diferenças estatisticamente significantes quando comparados meninos e meninas do grupo com desempenho escolar satisfatório, embora a média de desempenho escolar das meninas tenha sido maior. Em relação à percepção de seus professores, foram observadas diferenças nos dois grupos. Alunos com desempenho satisfatório se percebem mais elogiados e são escolhidos como ajudantes na sala de aula, enquanto alunos com desempenho insatisfatório acreditam receber mais críticas de seus professores e são vistos como mais indisciplinados. Os dados permitem discutir as relações vinculares entre alunos e professores, as influências das vivências e experiências no momento da aprendizagem e como essas influenciam o interesse e a motivação dos estudantes.

\section{Palavras-chave}

Relações interpessoais - Percepção de alunos - Desempenho escolar.

I- Universidade Estadual Paulista, Rio Claro, SP, Brasil.

Contato: selmacm@unicamp.br 


\title{
Academic achievement: comparative analysis by gender and student perception
}

Andréia Osti

Selma de Cássia Martinelli"

\begin{abstract}
This paper discusses the results of an investigation of academic achievement by gender and student perception of the expectations of their teachers. 120 students from the 5th year of primary education municipal public schools in the metropolitan region of Campinas city participated in the research: 60 of the students have satisfactory academic performance and the other 60 have unsatisfactory performance. We used a scale of student perception of teacher expectations and, to measure academic performance, we considered the grade teachers assigned to students. Research results revealed significant differences between boys and girls in the group of students with unsatisfactory performance, because most of them (83.3\%) were male. On the other hand, there were no statistically significant differences between boys and girls in the group with satisfactory academic performance, although girls' average academic performance was higher. Regarding the perception of their teachers, we observed differences in both groups. Students with satisfactory performance have the perception that they are more praised and more often chosen to assist the teacher in the classroom while underperforming students believe they receive more criticism from their teachers and are seen as more unruly. The data allow discussing student-teacher bond, the influence of experience at the time of learning and how it influences the interest and motivation of students.
\end{abstract}

\section{Keywords}

Interpersonal Relations - Perception of students - Academic achievement.

I- Universidade Estadual Paulista, Rio Claro, SP, Brazil.

Contact: aosti@rc.unesp.br:

II- Universidade Estadual de Campinas, SP, Brazil.

Contact:selmacm@unicamp.br 
A escola, seja no passado ou no momento atual, teve de enfrentar problemas com a evasão do aluno do sistema de ensino regular e com as altas taxas de reprovação. De fato, sempre foi muito difícil identifıcar com precisão o motivo que levava os alunos ao abandono da escola. A tentativa de abordar e enfrentar essas questões resultou em uma ampla literatura, que teve seu foco de atenção marcado na década de 80 no Brasil.

$\mathrm{Na}$ tentativa de buscar soluções a esses problemas e assumindo que grande parte deles poderia ser decorrente das condições sociais a que grande parte da população estava submetida, uma série de medidas governamentais foi tomada com o intuito de mudar essa realidade. A obrigatoriedade de permanência dos estudantes por no mínimo oito anos na escola e a criação de ciclos - por exemplo, o ciclo básico, que estipulava que o processo de alfabetização deveria ter uma duração mínima de dois anos e somente após esse período o aluno poderia ficar retido - foram apenas algumas dessas tentativas. Posteriormente, novas medidas foram criadas com a nova Lei de Diretrizes e Bases da Educação (Lei nº 9.394 - BRASIL, 1996), que instituiu ciclos mais longos de ensino, formalizando dois ciclos para o ensino fundamental, referentes ao ensino básico ( $1^{\mathrm{a}}$ a $4^{\mathrm{a}}$ série) e ao segundo ciclo ( $5^{\mathrm{a}}$ a $8^{\mathrm{a}}$ série).

Dessas mudanças, originou-se, no estado de São Paulo e em alguns outros estados do país, o regime de progressão continuada, que estabeleceu possíveis reprovações apenas ao f1nal de cada ciclo e não mais ao final de um ano, como ocorria antes. De forma geral, essas mudanças no sistema educacional brasileiro buscavam a melhoria do ensino, o combate à evasão e ao fracasso escolar.

Todos esses caminhos foram, de alguma forma, gerando outro cenário na educação. Atualmente, a evasão e a repetência escolar não são os problemas centrais, mas a defasagem e o baixo aproveitamento escolar por parte dos alunos, muitas vezes identificados como dificuldades de aprendizagem. Os dados do Censo Escolar de 2010 apontam que o índice de defasagem escolar no ensino fundamental chegou a 23,6\%, o que representa aproximadamente cerca de sete milhões de estudantes com defasagem escolar no país, ou seja, com idade incompatível com a série.

De acordo com o Instituto Nacional de Estudos e Pesquisas Educacionais (INEP), o rendimento dos estudantes é composto por quatro taxas: aprovação, reprovação, abandono e taxa de não resposta (matrícula sem informação suficiente para que o INEP possa categorizá-la). Ainda que em 2011 esse índice tenha sido reduzido, para cerca de 13\%, esses números ainda são preocupantes. Pode-se inferir que os índices apresentados evidenciam a insuficiência do trabalho realizado pela escola e reafirmam a necessidade de maior atenção à qualidade do ensino e da aprendizagem.

Com relação ao baixo aproveitamento escolar dos estudantes, os índices oficiais também revelam preocupação, uma vez que o nível de desempenho alcançado pelos estudantes brasileiros está aquém do observado em alunos de países desenvolvidos ou em desenvolvimento. Segundo dados do Programa Internacional de Avaliação de Alunos (PISA), divulgados em 2006, o Brasil estava na $49^{\circ}$ posição na prova de leitura e $54^{\circ}$ na avaliação de matemática. Na última edição do exame, em 2009, o Brasil ficou em 53 lugar.

Gomes e Boruchovitch (2009), ao traçar um panorama geral da proficiência em leitura de alunos brasileiros, afirmam que o desempenho dos mesmos no ensino fundamental e médio tem se revelado muito aquém dos objetivos visados pelos Parâmetros Curriculares Nacionais (PCNs). Pode-se considerar, pelos dados apresentados, e até mesmo pelo relato de professores e pais de estudantes, que a problemática da aprendizagem escolar se constitui um dos maiores desafios da contemporaneidade, conduzindo-nos à reflexão a respeito da temática das dificuldades e/ou do baixo desempenho escolar dos estudantes.

Os problemas das pessoas que têm enfrentado dificuldades durante o processo de 
aprendizagem podem estar associados a vários fatores. Lozano e Rioboo (1998) apontam para três: o contexto familiar e social, a personalidade do sujeito e as instituições educativas, incluindo suas áreas metodológicas e de organização. Somam-se a isso as considerações de Dolle e Bellano (2002), para quem as dificuldades de aprendizagem são decorrentes da interação entre a qualidade da instrução e as características emocionais e motivacionais dos alunos.

Muitos outros estudiosos têm procurado investigar os fatores associados ao baixo desempenho ou às dificuldades de aprendizagem dos estudantes. Esses estudos têm se centrado em diferentes aspectos e alguns deles apontam para as consequências emocionais vivenciadas pelos estudantes, como coloca Smith (2001), autor que alerta para o fato de os problemas de autoestima serem tanto causa como efeito das dificuldades, inclusive mais efeito que causa.

Rutter et al. (2008) enfatizaram a consequência emocional gerada pelo fracasso da criança em responder as demandas escolares e afırmam que, nessas situações, a criança deixa de confiar em si mesma e em suas possibilidades de sucesso, resistindo à aprendizagem e, muitas vezes, deixando de tentar realizar uma atividade por medo do fracasso.

Para Castro (2004), a base de todo processo de aprendizagem está na relação professor-aluno, a qual deve ser constituída como relação de troca de conteúdos, de conhecimentos e de afeto. Afirma ainda que essa relação nem sempre é igualitária, pois alguém detém mais conhecimento que outros. Assim, dependendo da maneira como o adulto se coloca nessa situação, ele pode auxiliar ou prejudicar o processo de aprendizagem.

Tomando como linha norteadora os aspectos apontados anteriormente, pode-se dizer que um elemento importante a se considerar no contexto escolar diz respeito à relação professor-aluno, uma vez que todo processo de aprendizagem perpassa pelas relações estabelecidas entre os envolvidos. Embora na escola muitas outras relações se estabeleçam, considera-se aquela que envolve o professor e o aluno é uma das principais, uma vez que o professor é a figura central, dentro desse contexto, e responsável por formalizar as interações do aluno com o conhecimento. 0 estudo dessa relação ganha força com a adoção do enfoque cognitivo. Como afirmam Abreu et al. (1983, p. 146):

[...] da perspectiva relacional do comportamento que o concebe como uma estrutura ou sistema de interações recíprocas, organismo-meio, sujeito-situação·ou Eumundo, sendo que cada um dos pólos não tem existência ou realidade psicológica sem o outro. (grifos dos autores)

Com essa perspectiva, muda-se a maneira de compreender o processo de aprendizagem. Segundo Coll e Solé (1996), talvez a mudança mais significativa tenha sido o deslocamento do olhar para o comportamento do professor e a metodologia utilizada para o interesse pelos mecanismos que influenciam a aprendizagem, dentre eles, a relação professor-aluno.

Nesse sentido, considera-se que, ao pensar a aprendizagem, não basta apenas analisar os problemas escolares, focando no conteúdo e/ou na metodologia adotada pelo professor. É preciso verificar também a relação entre professor e aluno. A maneira como o docente percebe o estudante pode levar a antipatias e simpatias que poderão facilitar ou dificultar o relacionamento e o vínculo em sala, afetando o desempenho do aluno e a maneira como o professor lida com ele.

Segundo Osti e Brenelli (2012), no decorrer do processo educativo, os alunos vão construindo percepções sobre si e podem aprender a se comportar em função das expectativas do professor em relação às respostas cognitivas e aos tipos de conduta por ele aceitas, segundo sua tolerância ou severidade.

A literatura tem apontado que as interações pessoais são também constituídas por percepções e expectativas de uma pessoa 
em relação à outra e que a expectativa de uma pessoa sobre o comportamento de outra pode, involuntariamente, tornar real a predição. As expectativas em relação ao outro influenciam na maneira como interagimos, respondemos a esse outro, bem como o que esperamos dele (ROSENTHAL; JACOBSON, 1968). Sabe-se também que grande parte das expectativas é gerada no contexto das próprias interações e sofrem a influência de inúmeros fatores, entre eles os nossos valores, as crenças que fomos construindo sobre as coisas, entre outros. Um dos elementos que influenciam nossos sistemas de crenças e expectativas é o sexo dos participantes.

As pesquisas de Rutter et al. (1979, 2008) evidenciam que há diferenças nas percepções dos alunos sobre a expectativa de seus professores. Afırmam que o desempenho do aluno melhora quando o professor se mostra mais disponível e pronto para atender seus problemas. Mostram ainda como a avaliação que o professor faz do aluno influencia o comportamento deste. Destacam que os alunos procediam e alcançavam um desempenho melhor quando os professores enfatizavam seu sucesso e potencial em comparação a quando esses focalizavam seus fracassos e pontos vulneráveis.

Também preocupadas com essa problemática, Schiavoni e Martinelli (2005) investigaram se crianças com diferentes níveis de dificuldades na escrita tinham percepções distintas a respeito das expectativas de seus professores sobre elas. Uma amostra de 138 crianças, com idades entre 9 e 10 anos de idade, foram selecionadas para participar da pesquisa. A escrita dos estudantes foi avaliada por meio de uma escala padronizada que detecta as dificuldades linguísticas mais comuns de crianças das séries iniciais do ensino fundamental. Também foi investigada a percepção dos estudantes sobre as expectativas de seus professores a seu respeito por meio de uma escala likert. As médias de percepção foram menores para os níveis mais altos de dificuldades na escrita e maiores para os grupos que apresentaram menos dificuldades de aprendizagem na escrita. Esse resultado indica que quanto maior o nível de dificuldade de aprendizagem dos participantes, menos positiva se mostrou a percepção que eles têm sobre as expectativas dos professores a seu respeito.

Martinelli e Schiavoni (2009), em um estudo posterior, também se propuseram a investigar se haveria relações entre a maneira com que os estudantes percebem as expectativas de seus professores a seu respeito e a aceitação dos mesmos pelos amigos da sala de aula. Foram selecionados 130 alunos do ensino fundamental, de ambos os sexos, entre 9 e 10 anos de idade, de duas escolas públicas do interior do estado de São Paulo.

Para avaliar o status sociométrico, foi solicitado aos participantes que indicassem três nomes de colegas da classe com quem gostariam e não gostariam de estudar e brincar. Os resultados mostraram que os alunos que revelaram acreditar que seu professor tinha uma percepção positiva a respeito deles também foram mais escolhidos pelos amigos tanto para estudar quanto para brincar e, por outro lado, os participantes que achavam que seus professores os viam de forma menos positiva também foram menos escolhidos por seus pares para as situações de estudo e brincadeiras.

No que se refere ao gênero, Gregoriadis e Tsigilis (2008) apontaram que os professores demonstram mais apoio e menos desaprovação às meninas, sendo que essas recebem mais elogios e carinhos do que os meninos. Outros estudos (CARVALHO, 2004, 2005; CASTRO, 2004; HENRIQUES, 2002; REZENDE, 2008) também apontaram para o fato de que os meninos apresentam maiores dificuldades em permanecer na escola ao longo dos anos escolares, recebem conceitos de avaliação inferiores, são mais indicados para reforço escolar, têm maiores índices de reprovação e estão mais presentes nos grupos considerados como tendo dificuldade de aprendizagem.

A escola, além de ser um ambiente dinâmico e diversificado e promotor de conhecimentos, também se constitui como local de socialização entre os indivíduos. Nesse contexto, 
as relações vivenciadas no ambiente da sala de aula e as percepções dos estudantes e professores podem contribuir para a construção e reprodução de estereótipos e discriminações, além de serem geradoras de expectativas.

Todas as formas de interação entre alunos e professores formam uma história constituinte de sua relação com o saber. No decorrer do processo educativo, as percepções desses sujeitos são construídas em um meio permeado tanto pelo cognitivo quanto pelo afetivo. 0 aprender deve ser pensado como uma responsabilidade compartilhada, sendo afetado tanto por fatores intrínsecos quanto extrínsecos. Nesse sentido, o processo de ensino e aprendizagem envolve professores e alunos, em um movimento em que as reflexões e percepções pessoais e interpessoais são primordiais, porque o sujeito para aprender precisa interagir com o outro.

Adotando essa perspectiva de análise, o presente estudo se propôs a investigar se existiriam diferenças entre os estudantes com desempenho escolar satisfatório e insuficiente no que se refere à percepção dos mesmos sobre as expectativas do professor a respeito desses alunos. Buscou-se também explorar as diferenças entre os sexos no que diz respeito à percepção do aluno quanto às expectativas de seu professor.

\section{Método}

Os participantes deste estudo foram 120 alunos, da rede pública municipal da região metropolitana de Campinas, sendo 51 (42,5\%) do sexo feminino e $69(57,5 \%)$ do masculino, com idades entre 10 e 14 anos. Todos os estudantes cursavam, no momento da coleta de dados, o $5^{\circ}$ ano do Ensino Fundamental. Dos 120 estudantes, 51,7\% tinham dez anos, o que correspondia à idade e série adequadas ao ano escolar cursado e os demais $(48,3 \%)$ tinham idades entre 11 e 14 anos, o que indicava defasagem com a série cursada. A metade da amostra, 60 estudantes, foi classificada como tendo adequado desempenho escolar e a outra metade tinha um desempenho insatisfatório.
Para avaliar a percepção do aluno, foi utilizada a escala de percepção de alunos sobre as expectativas dos professores (MARTINELLI; SCHIAVONI; BARTHOLOMEU, 2009). Essa escala contém 17 itens distribuídos em dois fatores, explicando 38\% da variância. 0 fator 1 , com nove itens, refere-se à percepção negativa das expectativas do professor por parte da criança e explicou 28,53\% da variância. Nessa dimensão, os itens sugerem percepções dos alunos de que o professor avaliaria os mesmos como mentirosos, culpados por brigas, desatentos, mal educados, pouco caprichosos e pouco estudiosos.

Por sua vez, o fator 2, com oito itens, relaciona-se à percepção positiva por parte da criança das expectativas do professor e foi responsável por 9,51\% da variância total. Esse tipo de percepção indicaria que o aluno percebe que o professor gosta dele, o elogia pelos deveres feitos, preocupa-se com ele e, ao mesmo tempo, acredita que os alunos são obedientes, fazem os deveres e são bem comportados. Nos coeficientes alfa de Cronbach, os valores foram 0,77 para o fator percepção positiva e 0,77 para percepção negativa das expectativas do professor. As opções de respostas para os itens da escala são: sempre, às vezes ou nunca.

Para as questões positivas do instrumento, são atribuídas a pontuação 2 para a resposta sempre, 1 para às vezes e 0 para nunca. Às questões negativas foram atribuídos valores inversos: 0 para a resposta sempre, 1 para às vezes e 2 para nunca, o que revela uma pontuação bruta para cada sujeito, sendo que a escala pode variar de 0 a 34 pontos, de modo a indicar que quanto maior a pontuação obtida, mais positiva é a percepção do sujeito.

Para medir o desempenho escolar, foi considerado o conceito atribuído ao aluno pelo professor. Convém esclarecer que nas escolas em que essa pesquisa foi realizada, as notas são definidas por conceitos. Assim, alunos com adequado desempenho acadêmico têm 
o conceito PS (plenamente satisfatório), MS (muito satisfatório) ou S (satisfatório), enquanto os alunos com baixo desempenho recebem NS (não satisfatório). 0 critério para selecionar os alunos que participaram desta pesquisa consistiu em ter conceitos PS, MS e NS. Para compor o grupo com desempenho insatisfatório, o aluno deveria ter o conceito NS e ser indicado por seu professor como sendo uma criança que apresenta dificuldade para aprender. Para compor o grupo com desempenho satisfatório, foram considerados apenas os estudantes que tiveram os conceitos PS e MS.

Inicialmente foi contatada a Secretaria de Educação do Município e solicitada permissão para a realização desta pesquisa nas escolas da rede. Devidamente autorizada, a pesquisadora agendou dia e horário com as escolas para apresentar a pesquisa à equipe gestora e professores. Após esse procedimento, foi feito contato com a família dos estudantes, entregues os termos de consentimento livre e esclarecido aos pais ou responsáveis e, mediante a aceitação em participar da pesquisa, foram agendados os dias e os horários para a aplicação do instrumento de acordo com o definido na Resolução 196/96. Somente integraram a pesquisa as crianças cujos pais autorizaram a participação. Nesse documento, constavam informações acerca do instrumento aplicado, bem como dos objetivos da pesquisa. Após obter o consentimento dos responsáveis, o instrumento foi aplicado individualmente na própria escola.

\section{Resultados}

Optou-se, neste estudo, pelo uso da metodologia quantitativa em decorrência dos objetivos propostos e do número de participantes da pesquisa. Os dados descritivos da amostra foram obtidos por meio do programa estatístico SPSS. As diferenças entre grupos foram analisadas por meio da prova estatística não paramétrica $U$ de Mann-Whitney.

\section{Análises descritivas do desempenho escolar em função do sexo}

As análises a seguir se detiveram a avaliar as diferenças, no interior de cada grupo, analisadas em função do sexo.

\section{Grupo com desempenho satisfatório}

Tabela 1- Comparação entre as médias por ranking em relação ao sexo

\begin{tabular}{c|c|c|c|c|c|c}
\hline Sexo & N & Média & U & Z & p \\
\hline Feminino & 41 & 31,50 & & & \\
\hline Masculino & 19 & 28,34 & 348,50 & $-0,654$ & 0,513 \\
\hline
\end{tabular}

Fonte: Dados da pesquisa.

Os dados da tabela 1 revelam que das 60 crianças do grupo com desempenho satisfatório 31,7\% são meninos e 68,3\% meninas. Ainda se pode verificar que a média de desempenho escolar das meninas foi mais elevada que a dos meninos, embora as diferenças verificadas não tenham sido estatisticamente significantes.

\section{Grupo com desempenho insatisfatório}

Tabela 2 - Comparação entre as médias por ranking em relação ao sexo

\begin{tabular}{|c|c|c|c|c|c|}
\hline Sexo & $N$ & Média & U & $z$ & $p$ \\
\hline Feminino & 10 & 46,80 & & & \\
\hline Masculino & 50 & 27,24 & 87,00 & $-3,243$ & 0,001 \\
\hline
\end{tabular}

Fonte: Dados da pesquisa.

A tabela 2 indica que existem algumas diferenças entre os alunos desse grupo com relação ao desempenho escolar. Os alunos do grupo com desempenho insatisfatório são, na maioria, meninos $(83,3 \%)$ e têm um desempenho mais baixo que as meninas. Ainda se pode verificar que a diferença observada entre esses estudantes foi estatisticamente significante. 
Análise comparativa dos grupos em relação à percepção de expectativas do professor

Os resultados comparativos entre os grupos com desempenho satisfatório e baixo desempenho revelaram que eles responderam diferentemente a escala de percepção de expectativas do professor e que essas diferenças foram estatisticamente significantes, como se pode observar na tabela 3.

Tabela 3 - Comparação entre as médias por ranking entre alunos com alto e baixo desempenho

\begin{tabular}{c|c:c:c:c:c}
\hline Desempenho & $N$ & Média & U & z & $p$ \\
\hline Desempenho Satisfatório & 60 & 89,47 & & & \\
\hline Desempenho Insatisfatório & 60 & 31,53 & 62,00 & $-9,132$ & $<0,001$ \\
\hline
\end{tabular}

Fonte: Dados da pesquisa.

Os alunos com desempenho satisfatório revelam ser mais elogiados por seus professores e escolhidos como ajudantes na sala de aula. Acreditam que são percebidos como bons alunos, bem comportados, obedientes. Também afırmam que o professor presta atenção neles quando solicitam ajuda, gostam do que fazem e se preocupam com eles.

Por outro lado, alunos com desempenho insatisfatório afirmam que recebem críticas de seus professores, os quais reclamam da falta de capricho em suas tarefas e não prestam atenção quando solicitam ajuda. Sempre que há uma briga na classe são apontados como culpados e declaram que o professor fica sempre zangado com esse grupo. Também acreditam que são vistos por seus professores como bagunceiros, mentirosos, aqueles que não prestam atenção na aula, os que estudam pouco e que tudo que fazem está errado.

\section{Discussão}

Dados estatísticos divulgados por Bloom, Cohen e Freeman (2009) no Sumary Health Statistics for U.S Children revelaram que 8\% dos estudantes americanos, na faixa etária de 3 a 17 anos, apresentavam dificuldades de aprendizagem, sendo que $11 \%$ eram meninos e 6\% meninas. Uma revisão de estudos conduzida por Liederman, Kantrowitz e Flannery (2005), em que eram investigadas as dificuldades de leitura, também revelou haver um predomínio de meninos em relação às meninas com dificuldades. Assim, pode-se afırmar que são os meninos, de maneira geral, a encabeçarem as estatísticas por apresentarem maiores índices de reprovação, evasão e dificuldades.

Os dados encontrados no presente estudo também apontam para essa mesma direção, uma vez que os meninos apresentaram menor desempenho durante o ano escolar, em comparação com as meninas de mesma idade e série cursada. Esse resultado está em consonância também com outros trabalhos.

Conforme apontado por Rezende (2008), os meninos (sobretudo os pardos e negros) apresentam uma situação escolar bastante desvantajosa em comparação com as meninas (brancas e negras) e meninos brancos. 0 primeiro grupo apresenta maiores índices de reprovação, evasão, recebem conceitos de avaliação inferiores e são mais indicados para reforço escolar.

Ao investigar os processos que têm conduzido um maior número de meninos do que meninas a obter conceitos negativos e a ser indicado para atividades de recuperação, Carvalho (2005) observou que as diferenças de desempenho entre os sexos parecem ser mais significativas, com os meninos predominando largamente entre os indicados para reforço, em todos os grupos de raça e faixas de renda. Outros estudos (CASTRO, 2004; GREGORIADIS; TSIGILIS, 2008; HENRIQUES, 2002; LINDGARD; DOUGLAS, 1999) também afirmam que frequentemente há maior presença dos meninos nas atividades de reforço escolar e atendimento especial do que meninas. Nas pesquisas de Osti (2010) e Osti e Brenelli (2012), realizadas com alunos de escolas públicas da região metropolitana de Campinas, as autoras destacam que os alunos considerados com dificuldades foram em sua maioria meninos (85\%). 
Apesar dessa indicação, é importante pontuar que ainda são poucos os estudos que avaliam as diferenças entre os sexos. Dentre esses, nem sempre são concordantes entre si e nem tampouco são suficientes para interpretar essas diferenças. Conforme apontado por Liederman; Kantrowitz e Flannery (2005), é necessário que outros estudos sejam conduzidos a fim de comparar o desempenho de meninas e meninos. Os autores enfatizam que esses estudos deveriam ser conduzidos utilizando outras formas de medição e definição da habilidade ou do constructo a ser avaliado, comparando o desempenho de meninos e meninas em relação ao seu próprio grupo e não intergrupos e relatando as diferenças e a variabilidade das relações obtidas entre os grupos.

Por outro lado, e já há bastante tempo, os estudos voltados para a análise do desempenho escolar dos estudantes têm apontado para o fato de que o sucesso escolar implica uma reunião de fatores que incluem a boa relação do aluno com seu professor, sua autoestima, participação da família e a adaptação escolar, dentre muitas outras condições. Portanto, não se pode apontar o aluno como o único responsável por seu sucesso ou fracasso na aprendizagem, pois são vários os fatores que contribuem para uma experiência bem sucedida de aprendizagem. Da mesma maneira, não se pode responsabilizar somente o professor pelo sucesso de um percurso, uma vez que o desempenho de suas funções também sofre a influência não só das circunstâncias imediatas, mas também da existência de um macro contexto que pode se revelar muito complexo.

A análise detalhada e concomitante desses aspectos é de difícil operacionalização quando se trata de investigar esses fenômenos em uma situação de contexto natural, como o que está presente no dia a dia do funcionamento escolar, onde geralmente as pesquisas são realizadas. Apesar dessas dificuldades, a vivência escolar sempre revela dados da realidade bastante importantes e que se constituem em campo fértil e rico de informações sobre a vida e a aprendizagem dos estudantes. Assim, a maioria dos estudos tem optado por fazer recortes dessa realidade, a fim de analisar e conhecer os aspectos que, ao estarem presentes nesse contexto, podem interferir de forma positiva ou negativa sobre a aprendizagem e o desenvolvimento afetivo, cognitivo e social dos estudantes.

Conforme pontuam Rutter et al. (2008), as expectativas dos professores têm sido objeto de investigação há várias décadas, por se considerar que elas influenciam o progresso acadêmico dos alunos. Os autores destacam que os alunos não apenas percebem quais são as expectativas que seus professores fazem de sua competência acadêmica e de seu comportamento como acabam por corresponder a elas. Exemplificam relatando estudos em que os alunos obtiveram mais sucesso acadêmico quando os professores expressavam expectativas de que as crianças se sairiam bem nos exames.

Essa colocação pode ser mais bem exemplificada a partir dos dados revelados por este estudo, que mostraram haver diferenças entre os grupos de estudantes com relação à percepção de seus professores. Alunos com desempenho satisfatório revelam ser mais elogiados por seus professores e escolhidos como ajudantes na sala de aula. Por outro lado, alunos com desempenho insatisfatório afirmaram receber mais críticas de seus professores e também acreditam ser percebidos como bagunceiros e mentirosos.

Como os dados do presente estudo revelam as percepções dos estudantes, não se pode afırmar serem essas condições verdadeiras ou não. No entanto, apesar dessa limitação, também é importante frisar que somos constantemente influenciados por nossas percepções e em função delas agimos e reagimos diante das situações. Nesse sentido, pode-se dizer que as percepções dos alunos a respeito da maneira como pensam e sentem as relações com seus professores têm influência sobre seu desempenho.

Se o aluno percebe ou sente em seu professor o descrédito em sua capacidade, possivelmente terá menos vontade de participar da aula e poderá, em alguns casos, assumir para si a falta de condições para aprender. Essas 
condições são ainda mais fortes em crianças que estão no início do processo de escolarização, uma vez que, nesse momento, é o professor quem assume importância fundamental, por ser a figura adulta e externa à família com a qual as crianças passam a se identificar.

Assumindo essa perspectiva, é possível afirmar que os alunos podem ser influenciados pelo modo como são tratados por seus professores. Dessa forma, os estudantes, ao vivenciarem relações positivas, tendem a se sentir mais confortáveis e seguros. Por outro lado, quando vivenciam relações negativas, podem desenvolver atitudes de rejeição em relação à escola, desvalorização pessoal e baixo rendimento. Além disso, Rutter et al. (2008) afirmam que o comportamento do estudante é melhor quando os professores fazem uso de elogios, assim como enfatizam o bom comportamento. Os alunos tendem a aprender melhor quando ensinados em um clima de confiança. Também ressaltam que as repreensões e castigos podem provocar e perpetuar a indisciplina e aumentar a probabilidade da criança demonstrar comportamento agressivo.

Dessa maneira, os dados do presente estudo, associados aos demais que têm se detido sobre a análise das relações entre professores e alunos, nos levam a refletir a respeito do quanto as relações vinculares entre alunos e professores são importantes durante todo o processo escolar e além dele. Isso porque as relações com o conhecimento sofrem influências de vivências e experiências com a aprendizagem, as quais podem tanto favorecer quanto inibir o interesse, a criatividade, a motivação, entre outros aspectos necessários ao ato de conhecer.

\section{Referências}

ABREU, Manuel Viegas et al. Da prevenção do insucesso escolar ao desenvolvimento interpessoal. Revista Portuguesa de Pedagogia, Coimbra, Universidade de Coimbra, v. 17, p 143-170, 1983.

BRASIL. Lei nº 9394, de 20 de dezembro de 1996. Estabelece as diretrizes e bases da educação nacional. Diário Oficial da União, Brasília, DF, 1996.

BLOOM, Barbara; COHEN, Robin A., FREEMAN, Gulnur. Summary health statistics for U.S. children: National Health Interview Survey, 2009. National Center for Health Statistics. p.1-48, 2009. (Vital and health statistics , séries 10, n.247, 2010).

CARVALHO, Marília Pinto. Quem são os meninos que fracassam na escola? Cadernos de Pesquisa, v. 34, n. 121, p. 11-40, 2004. Disponível em: <http://www.scielo.br/pdf/cp/v34n121/a02n121.pdf>. Acesso em: 09 set. 2012.

. Quem é negro, quem é branco: desempenho escolar e classificação racial de alunos. Revista Brasileira de Educação, Rio de Janeiro, v. 28, 2005. Disponível em: <http://www.scielo.br/scielo.php?script=sci_arttext\&pid=S1413-24782005000100007>. Acesso em: jul. 2013.

CASTRO, Maria Luiza Garitano de. 0 olhar psicopedagógico na instituição educacional: o psicopedagogo como agente de inclusão social. Revista Psicopedagogia, v. 21, n. 65, p. 108-116, 2004.

COLL, César; SOLÉ, Isabel. A interação professor/aluno no processo de ensino e aprendizagem. In: COLL, César; PALACIOS, Jesús; MARCHESI, Álvaro. (Orgs.). Desenvolvimento psicológico e educação, v. 2, Porto Alegre: Artes Médicas, 1996.

DOLLE, Jean-Marie; BELLANO, Denis. Essas crianças que não aprendem: diagnóstico e terapias cognitivas. Petrópolis, RJ: Vozes, 2002.

GOMES, Maria Aparecida Mezzalira; BORUCHOVITCH, Evely. Proficiência em leitura: um panorama da situação. In: SANTOS, Acácia Aparecida Angeli; BORUCHOVITCH, Evely; OLIVEIRA, Katya L. Cloze: um instrumento de diagnóstico e intervenção. São Paulo: Casa do Psicólogo, 2009. 
GREGORIADIS, Athanasios; TSIGILIS, Nikolaos. Applicability of the student teacher relationship scale (STRS) in the Greek education setting. Journal of Psychoeducational Assessment, Sage Publications, v. 26, n. 2, p. 108-122, 2008.

HENRIQUES, Ricardo. Raça e gênero nos sistemas de ensino: os limites das políticas universalistas em educação. Brasília, UNESCO, 2002.

LIEDERMAN, Jacqueline; KANTROWITZ, Lore; FLANNERY, Kathleen. Male vulnerability to reading disability is not likely to be a myth: a call for new data. Journal of Learning Disabilities, v. 38, n. 2, p. 109-129, 2005.

LINDGAR, Bob; DOUGLAS, Peter. Men engagin feminisms: pro-feminsm, backlashes and schooling. Buckinghan: Opens University Press, 1999.

LOZANO, A. Barca; RIOBOO, A. Porto. Dificultades de aprendizaje: categorias y clasificación, factores, evaluacíon y proceso de intervencíon psicopedagógica. In: SANTIUSTE, Víctor Bermejo; BÉLTRAN, Jesús. Dificultades de aprendizaje. Madrid: Síntesis, 1998.

MARTINELLI, Selma de Cássia; SCHIIVONI, Andreza; BARTHOLOMEU, Daniel. Propriedades psicométricas de uma escala de percepção de alunos sobre as expectativas do professor avaliação psicológica. Avaliação Psicológica, Porto Alegre, v.8, n.1, p. 119-129, 2009.

Percepção do aluno sobre sua interação com o professor e status sociométrico. Estudos de Psicologia, Campinas, v. 26, n. 3, p. 327-336, 2009.

OSTI, Andreia. Representações de alunos e professores sobre ensino e aprendizagem. 2010. Tese (Doutorado em Educação). Faculdade de Educação da Universidade Estadual de Campinas - UNICAMP, Campinas, 2010.

; BRENELLI, Roseli Palermo. Análise comparativa de representações de alunos e professores sobre as relações entre ensino e aprendizagem. Revista Educação Temática Digital, Campinas, v. 14, n. 1, p. 365-385, 2012.

REZENDE, Andréia Botelho de. Questão de gênero e raça: o desempenho escolar de meninos negros. In: SEMINÁRIO INTERNACIONAL FAZENDO GÊNERO, 8, 2008, Florianópolis. Anais... Florianópolis: UFSC, 2008. Disponível em: <www.fazendogenero.ufsc.br/8/sts/ ST51/Andreia_Botelho_de_Rezende_51.pdf>. Acesso em: 13 set. 2012.

ROSENTHAL, Robert; JACOBSON, Lenore. Pygmalion in the classroom: teacher expectation and pupil's intellectual development. New York: Holt, Rhinehat \& Winston, 1968.

RUTTER, Michael et al. Fifteen thousand hours: secondary schools and their effects on children. London: Open Books, 1979.

Conclusões, especulações e implicações. In: BROKE, Nigel; SOARES, José Francisco. Pesquisa em eficácia escolar. Belo Horizonte, UFMG, 2008.

SCHIAVONI, Andreza; MARTINELLI, Selma de Cássia. Percepção de alunos sobre as expectativas do professor acerca de seu desempenho: um estudo comparativo entre alunos com e sem dificuldades de aprendizagem. Interação em Psicologia, Curitiba, v. 9, n. 2, p. 311-319, 2005.

SMITH, Peter K.; PELLEGRINI, Anthony D. Psychology of education: major themes. London: TJ International, 2001.

Recebido em: 11.08.2012

Aprovado em: 26.02.2013

Andréia Osti é doutora em Educação pela Universidade Estadual de Campinas. Professora do Departamento de Educação do Instituto de Biociências da Universidade Estadual Paulista - UNESP.

Selma de Cássia Martinelli é professora livre docente pela Universidade Estadual de Campinas. Professora do Departamento de Psicologia Educacional da Faculdade de Educação da UNICAMP e Coordenadora do Grupo de Estudos e Pesquisa em Psicopedagogia. 